\title{
PENGEMBANGAN MODEL TASAWUF OLEH GURU NGAJI SEBAGAI BASIS PEMBINAAN AKHLAK SANTRI DI TPQ AL-KHAIRAT RASABOU KOTA BIMA
}

\begin{tabular}{|c|c|c|c|}
\hline & & $\begin{array}{r}\text { STIT } \\
\text { Email: } \underline{\text { salamrah }}\end{array}$ & $\begin{array}{l}\text { Abd. Salam } \\
\text { an Giri Bima - NTB } \\
\text { a1234@yahoo.co.id }\end{array}$ \\
\hline Received : & Submit : & Edited : & Published : \\
\hline 02 Agustus 2020 & 02 Agustus 2020 & 02 Agustus 2020 & 04 Agustus 2020 \\
\hline
\end{tabular}

\begin{abstract}
Sufism is managing spiritually with commendable morals, but Sufism is also as soul worship through the tazkiyatun nafs method. Sufism is one of the sciences that can foster the morals of students because there is knowledge in it is the teachings of morals. Sufism models in TPQ AL-KHAIRAT taught and developed by the teacher of the Koran to their students are learning that focuses on fostering the values of the aqeedah and the morals of the female students in educational institutions, starting from the level of education in the TPQ AL-KHAIRAT to basic education to higher education . Therefore, it is important for students to be guided by spiritual values through the Sufism model in learning activities such as; good speech, well dressed, including ethical ones get along well. The students are implanted in a perfect manner, such as values Always eagerly recite the Qur'an every day, daily wear gloves and hats, daily use of reading books, always close to the mosque to worship Allah SWT, be patient in all aspects of life sentences toyyibah, Consistent carrying out the prayer even though in a state of pain, Always be careful in saying and doing. In order for female students to be able to differentiate between Sufi models of ijma ulama and those of Sufi dolalah and be able to have spiritual values, it must be instilled into the souls of the female students and maintain harmony between the Koran teachers with students and parents of students in the scope of education.
\end{abstract}

Keywords : Model of Sufism, Value of Sufism, Morals

\begin{abstract}
ABSTRAK
Tasawuf adalah mengelola rohani dengan akhlak yang terpuji, akan tetapi tasawuf juga sebagai penyujian jiwa melalui metode tazkiyatun nafs. Tasawuf merupakan salah satu ilmu yang dapat membina akhlak santri-santriwati karena terdapat ilmu di dalamnya adalah ajaran akhlak. Model tasawuf di TPQ AL-KHAIRAT yang diajarkan dan dikembangkan oleh guru ngaji kepada santrinya merupakan pembelajaran yang fokus pada pembinaan nilai akidah dan akhlak santri-santriwati di lembaga pendidikan, mulai dari jenjang pendidikan yang ada di TPQ AL-KHAIRAT hingga pendidikan dasar sampai pendidikan tinggi. Oleh karena itu, penting bagi Santri-santriwati agar dibimbing dengan nilai-nilai rohani melalui model tasawuf dalam aktivitas pembelajaran seperti; cara tutur kata yang baik, berpakaian yang baik, teramsuk tentang yang etika bergaul dengan baik. Santri-santriwati ditanamkan sifat-sifat yang paripurna, seperti nilai-nilai Selalu membumikan al-Qur'an setiap harinya, Keseharianya memakai sarung dan topi, Keseharianya memanfatkan membaca buku, Selalu dekat dengan masjid untuk beribadah kepada Allah SWT, Sabar dalam segala aspek kehidupan, Ketika ia sakit selalu mengucapkan kalimat-
\end{abstract}


kalimat toyyibah, Konsisten melaksanakan ibadah sholat walaupun dalam keadaan sakit, Selalu berhati-hati dalam berucap dan berbuat. Agar santri-santriwati dapat membedakan mana model tasawuf ijma ulama dan mana tasawuf dolalah serta dapat memiliki nilai-nilai rohani maka harus ditanamkan kedalam jiwa santri-santriwati tersebut dan menjaga keharmonisan antara guru ngaji dengan santri maupun orang tua peserta didik dilingkup pendidikan.

\section{Kata Kunci: Model Tasawuf, Nilai Tasawuf, Akhlak}

\section{PENDAHULUAN}

Tasawuf merupakan mengenal diri yang sesungguhnya karena tanpa mengenal diri maka tidak akan mengenal Allah SWT. Jadi tasawuf juga salah satu ilmu yang dapat membina akhlak santri-santriwati karena terdapat ilmu di dalamnya adalah ajaran akhlak.

Tasawuf merupakan suatu upaya pendekatan diri pada Allah SWT. melalui kesadaran murni dengan memengaruhi jiwa secara benar untuk melakukan berbagai latihan-latihan (riyadlah), baik secara fisik maupun mental, dan dengan melakukan berbagai ibadah sehingga aspek uluhiyah dan ruhaniyah dapat mengungguli aspek duniawiyah dan jasadiyah. Jadi di tasawuf bukanlah perpindahan dari alam fisik (kebendaan) ke alam rohani, yang mempunyai implikasi bahwa sufi akan meninggalkan materi.

Tasawuf itu merupakan suatu ijtihad dan jihad (upaya sungguh) untuk mengeliminasi dominasi materi dalam kehidupan. Artinya, materi masih tetap dibutuhkan sebagai sarana mencapai tujuan hidup, mendekatkan diri kepada Allah SWT. ${ }^{1}$

Dari apa yang disampaikan oleh Syamsun Ni'am di atas mengandung pengertian bahwa tasawuf bukanlah perpindahan dari alam fisik (kebendaan) ke alam rohani, yang mempunyai implikasi bahwa sufi akan meninggalkan materi atau dengan kata lain tasawuf segala apa yang terdapat di dunia ini akan kita tinggalkan yang ada hanya amalan selama hidup kita.

Maka dengan lahirnya model tasawuf ini sebagai pembinaan akhlak adalah sangat signifikan di dalam pembinaan akhlak santri-santriwati, Karna tasawuf mengelola rohani dengan akhlak yang terpuji tetapi juga tasawuf adalah penyujian jiwa.

Penyucian jiwa sesungguhnya bertujuan untuk mengembalikan manusia kepada fitrahnya, yaitu fitrah tauhid, fitrah iman, Islam, dan ihsan, disertai dengan upaya menguatkan dan mengembangkan potensi tersebut agar setiap orang selalu dekat kepada Allah, menjalaknkan segala ajaran dan kehendak-Nya, dan menegakkan tugas dan misinya sebagai hamba dan khalifah-Nya di bumi. ${ }^{2}$

${ }^{1}$ Syamsun Ni’am, Tasawuf Studies, Pengantar Belajar Tasawuf, Yogyakarta: Ar-Ruzz Media, 2014),

${ }^{2}$ Abd. Salam, Tasawuf Jalan Rohani Menuju Allah, (Malang: Penerbitan UMM Pres, 2015), 19. 
Pendidikan kita sekarang ini harus ada pembenahan baik di lingkungan keluarga maupun di lingkungan masyarakat. Pembinaan akhlak di TPQ AL-KHAIRAT adalah sebagai pembinaan dasar akhlak dan perlu dipupuk atau di perkuat melalui model tasawuf ini.

"Tasawuf adalah suatu bidang ilmu keislaman dengan berbagai pembagian didalamnya, yaitu tasawuf akhlaqi, tasawuf amali, tasawuf falsafi. Tasawuf akhlaqi berupa ajaran mengenai moral/akhlak yang hendaknya diterapkan dalam kehidupan sehari-hari terutama diterapkan tasawuf ini di dunia pendidikan guna memperoleh kebahagiaan yang optimal."3

Pembinaan akhlak adalah proses pembangunan perilaku santri-santriwati secara bertahap yang dilakukan oleh guru ngaji sebagai implementasi dari iman dan ajaran Islam dalam kehidupan induvidu, keluarga, masayarakat dan negara.

Pembinaan akhlak adalah proses perbuatan, tindakan, penanaman nilai-nilai perilaku budi pekerti, perangai, tingkah laku baik terhadap Allah Subhanahu Wa Ta'ala, sesama manusia, diri sendiri dan alam sekitar yang dilakukan secara berdaya guna dan berhasil guna untuk memperoleh kebahagiaan hidup di dunia dan di akhirat. ${ }^{4}$

Pembinaan akhlak yang dilakukan TPQ Al-Khairat melalui semua materi model tasawuf yang disampaikan oleh guru ngaji bertujuan agar santri-santriwati dapat memahami dan mengamalkan ajaran Islam dan menggunakanya sebagai pedoman hidup (way of life) dan berakhlak mulia sesuai dengan ajaran Islam serta membentuk santri-santriwati yang memiliki keyakinan dan kepribadian yang baik.

\section{METODE PENELITIAN}

Peneliti ini merupakan penelitian lapangan dengan menggunakan penedekatan kualitatif. Tempat penelitian dilaksanakan di Tpq Al-Khairat Ling. Rasabou, yang beralamat di kelurahan Jatibaru Kec. Asakota Kota Bima merupakan Tpq yang terunggul dalam Penguatan Nilai-nilai Karakter Santri-Santriwati Melalui Bacaan Al-Qur'an di Kota Bima. Selain itu juga Tpq Al-Khairat Ling. Rasabou juga merupakan ujung tombak perkembangan nilai-nilai karakter serta bacaan Al-Qur'an di Tpq Al-Khairat Ling. Rasabou.

Metode Analisis Data

Teknik analisis data merupakan upaya mencari dan menata secara sistematis catatan hasil observasi, wawancara dan lainnya untuk meningkatkan pemahaman peneliti tentang

${ }^{3}$ M. Amin Syukur, Tasawuf kontekstual, Solusi Problem Manusia Modern, (Yogyakarta, Pustaka Pelajar, 2003), 1.

${ }^{4}$ Azmi, Muhammad. Pembinaan Akhlak Anak Usia Pra Sekolah. Solo: Belukar, 2006, 56. 
kasus yang diteliti dan menyajikannya sebagai temuan bagi orang lain. Dalam menganalisa data, peneliti akan menggunakan teknik deskriptif analitik, yaitu data yang diperoleh tidak dianalisa menggunakan rumusan statistika, namun data tersebut didetesiskan sehingga dapat memberikan kejelasan sesuai kenyataan realita yang ada di lapangan.

Hasil analisa berupa pemaparan gambaran mengenai situasi yang diteliti dalam bentuk uraian naratif. Uraian pemaparan harus sistematik dan menyeluruh sebagai satu kesatuan dalam konteks lingkungannya juga sistematik dalam penggunaannya sehingga urutan pemaparannya logis dan mudah diikuti maknanya. ${ }^{5}$ Jadi analisis ini akan peneliti gunakan untuk menganalisa tentang bagaimana Penguatan Nilai-nilai Karakter Santri-Santriwati Melalui Bacaan Al-Qur'an di Tpq Al-Khairat Ling. Rasabou Kel. Jatibaru Kec. Asakota Kota Bima.

Adapun langkah-langkah analisis yang peneliti lakukan selama di lapangan adalah: 1). Reduksi Data. Mereduksi data berarti merangkum, memilih hal-hal yang pokok, memfokuskan pada hal-hal yang penting, dicari tema dan polanya dan membuang yang tidak perlu. ${ }^{6}$ Dengan demikian data yang di reduksi akan memberikan gambaran yang cukup jelas. 2). Penyajian Data. Setelah data direduksi, maka langkah selanjutnya adalah mendisplaykan data, sehingga data dapat terorganisasikan dan dapat semakin mudah dipahami. 3). Penarikan Kesimpulan. Langkah ketiga adalah penarikan kesimpulan dan verifikasi.

Kesimpulan awal yang ditemukan masih bersifat sementara dan akan berubah bila tidak ditemukan bukti-bukti yang kuat mendukung pada tahap pengumpulan data berikutnya. Tetapi apabila kesimpulan yang dikemukakan pada tahap awal didukung oleh bukti-bukti yang valid dan konsisten saat peneliti kembali kelapangan mengumpulkan data, maka kesimpulan yang dikemukakan merupakan kesimpulan yang kredibel.

Berdasarkan paparan tersebut peneliti menggunakan teknik analisis kualitatif dalam penelitian untuk mengkaji "Penguatan Nilai-nilai Karakter Santri-Santriwati Melalui Bacaan Al-Qur'an di Tpq Al-Khairat Ling. Rasabou Kel. Jatibaru Kec. Asakota Kota Bima”.

${ }^{5}$ Nana Sudjana, dan Ibrahim, Penelitian dan Penelitian Kualitatif, (Bandung : Sinar Baru, 1989), $197-$ 198.

6 Sugiyono, Metode Penelitian Pendidikan Pendekatan Kuantitatif, Kualitatif dan R\&D, (Bandung: Alfabeta, 2009), 92. 


\section{PEMBINAAN AKHLAK DENGAN MODEL TASAWUF}

Tasawuf secara bahasa/etimologis berasal dari kata: 1). Shaff, yang berarti saf atau baris; 2). Shafa yang berarti bersih; 3). Shuffah atau shuffat al-masjid, serambi masjid; 4). Shuf, yang berarti bulu domba; 5). Sophos (bahasa yunani) yang berarti hikmah (kebijaksanaan); 6). Shaufana, yaitu sejenis buah-buahan (a kind of vegetable), yang berbentuk kecil dan berbulu yang banyak tumbuh di gurun pasir Arab; 7.) Shuffah, artinya suatu kamar di samping Masjid Nabawi yang disediakan untuk sahabat Nabi dari golongan Muhajirin yang miskin.

Tasawuf secara istilah/terminologis: 1). Tasawuf adalah pengetahuan tentang semua bentuk tingkah laku jiwa manusia, baik yang terpuji maupun tercela; kemudian bagaimana membersihkanya dengan yang terpuji, bagaimana menempuh jalan kepada Allah dan berlari secepatnya menuju kepada Allah; 2). Sufi adalah yang mewarisi ilmu dan amal Rasulullah SAW., juga mewarisi akhlak yang sesuai dengan batin (mental) beliau yang berupa: zuhud, wara', takut (kepada Allah), kecintaan (kepada Allah dan segala yang dicintai oleh-Nya), dan ma'rifah (penghayatan yang tuntas tentang ketuhanan.

Tujuan pendidikan Tasawuf adalah untuk membentuk akhlak yang mulia menjadikan ajaran tasawuf tersebut yakni menciptakan manusia yang berakhlakul karimah. Jadi Pembinaan akhlak melalui tasawuf sangatlah penting pada setiap anak terutama pada santrisantriwati TPQ Al-Khairat. Tujuan pendidikan Tasawuf adalah untuk membentuk akhlak yang mulia menjadikan ajaran tasawuf tersebut yakni menciptakan manusia yang berakhlakul karimah.

Akhlak artinya perbuatan atau kepribadian yang secara keseluruhan aspeknya, sebagai perilaku yang ditampilkan, sesuai dengan ajaran Islam aktifitas kejiwaannya, falsafah hidup dan kepercayaannya menunjukkan rasa pengabdian dan penyerahan diri kepada Allah SWT.

Romantika Al-Qur'an Mengatakan:

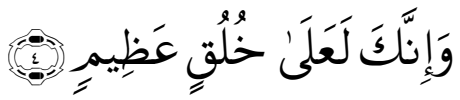

Artinya: Dan Sesungguhnya kamu benar-benar berbudi pekerti yang agung. (QS. AlQalam:4).

Dari definisi ayat di atas dapat disimpulkan bahwa dalam menjabarkan akhlak universal diperlukan bantuan pemikiran akal manusia dan kesempatan sosial yang terkandung dalam ajaran etika dan moral. Menghormati kedua orang tua misalnya adalah akhlak yang bersifat mutlak dan universal. Sedangkan bagaimana bentuk dan cara menghormati orang tua 35 .

${ }^{7}$ Syamsun Ni'am, Tasawuf Studies, Pengantar Belajar Tasawuf, Yogyakarta: Ar-Ruzz Media, 2014), 
itu dapat dimanifestasikan oleh hasil pemikiran manusia. Jadi, akhlak Islam bersifat mengarahkan, membimbing, mendorong, membangun peradaban manusia dan mengobati bagi penyakit sosial dari jiwa dan mental, serta tujuan berkarakter yang baik untuk mendapatkan kebahagiaan di dunia dan akhirat.

Dalam proses pembinaan terhadap santri-santriwati, guru ngaji berupaya mewujudkan tiga aspek akhlak tersebut secara harmonis yaitun aspek kejasmanian, aspek kejiwaan, dan aspek keharmonisan, dengan mewujudkan ketiga aspek tersebut dapat menciptakan keseimbangan yang terpadu secara integritas akhlak.

Yang dimaksud dengan integritas akhlak ialah proses yang terpadu dari pembangunan karakter setiap manusia yaitu sesuatu pertumbuhan yang menumbuhkan kesatuan unsur-unsur jasmani dan rohaniah menjadi bangunan yang harmonis sebagai akibat terjalinnya mekanisme sistem pengaturan yang tertib, teratur dan rapi. ${ }^{8}$

Adapun Pembagian tasawuf yakni sebagai berikut; pertama, Tasawuf akhlaqi adalah tasawuf yang berkonstrasi pada teori-teori perilaku, akhlaq atau budi pekerti atau perbaikan akhlaq. Dengan metode-metode tertentu yang telah dirumuskan, tasawuf seperti ini berupaya untuk menghindari akhlaq mazmunah dan mewujudkan akhlaq mahmudah.

Kedua, Tasawuf Falsafi adalah tasawuf yang didasarkan kepada gabungan teori-teori tasawuf dan filsafat atau yang bermakana mistik metafisis, karakter umum dari tasawuf ini sebagaimana yang telah dikemukakan oleh Al-Taftazani bahwa tasawuf seperti ini: tidak dapat dikatagorikan sebagai tasawuf dalam arti sesungguhnya, karena teori-teorinya selalu dikemukakan dalam bahasa filsafat, juga tidak dapat dikatakan sebagai filsafat dalam artian yang sebenarnya karena teori-teorinya juga didasarkan pada rasa. Hamka menegaskan juga bahwa tasawuf jenis tidak sepenuhnya dapat dikatakan tasawuf dan begitu juga sebaliknya.

Dengan pembatinan itu melaksanakan ajaran Islam secara sempurna. Sebab seorang harus merasakan setiap saat ia berada di hadapan Tuhan, dia harus selalu berlaku penuh hormat dan puja, jangan sampai terjerumus lagi kedalam "lelap dalam kelalaian," dan tak pernah melupakan kehadiran Illahi yang merengkuh segalanya.

Maka ihsan atau tasawuf meliputi semua tingkah laku, baik tindakan lahiriah maupun batini, dalam ibadah maupun mu'amalah. Sebab ihsan atau tasawuf adalah jiwa atau roh dari iman dan Islam. Iman sebagai fondasi yang ada pada jiwa seseorang dari hasil berpaduan antara ilmu dan keyakinan. Penjilmaanya yang berupa tindakan badaniah (ibadah lahiriah) di sebut Islam. Sebagaimana dikatakan bahwa tasawuf adalah akhlak.

${ }^{8}$ Suparlan Suryapratondo, Ilmu Jiwa Kepribadian, (Jakarta : PT. Paryu Berkah, 1984), 116. 
Tasawuf bukan hanya sekedar tulisan dan ilmu, tetapi ia adalah akhlak. Sekiranya ia adalah tulisan maka ia akan didapatkan dengan bersungguh-sungguh dan seandainya ia adalah ilmu maka akan diperoleh dengan belajar. Tetapi tasawuf adalah berakhlak dengan akhlak Allah, sekali-kali tidak akan dapat dicapai dengan ilmu dan tulisan."

Implementasi tasawuf adalah imtaq mengarah kepada pendidikan akhlak, yang lebih mengedepankan sikap kesehajaan dan ibadah yang banyak untuk mencapai kedamaian hidup dan kedekatan diri kepada Allah, yang harus dilalui dari tahap penyucian diri (tazkiyat al-nafs) dan merasakan kehadiran Allah dalam kehidupan sehari-hari.

Ihsan atau tasawuf dalam uraian di atas juga dapat diterjemahkan dengan sempurna yang bermakna bahwa perbuatan baik terwujud dalam penyerahan diri sepenuhnya kepada Allah, karena hanya kepada-Nya segala urusan dikembalikan. Berserah diri kepada Allah merupakan ciri khusus yang dimiliki orang-orang mukmin yang ber-ihsan, yang memiliki keimanan yang mendalam, yang mampu melihat kekuasaan Allah, dan yang dekat denganNya, merasakan senatiasa kehadiran-Nya dimanapun ia berada, dan selalu mengagungkanNya serta selalu memohon pertolongan kepada-Nya.

\section{Akhlak}

Pengertian Akhlak Secara Etimologi, Menurut pendekatan Etimologi, perkataan “Akhlak" berasal dari Bahasa Arab Jama' dari bentuk mufradnya "Khuluqun) yang Omenurut logat diartikan: budi pekerti, perangai, tingkahlaku atau tabiat.

Akhlak adalah perbuatan suci yang terbit dari lubuk jiwa yang paling dalam, karenanya mempunyai kekuatan yang benar. Akhlak sering pula disebut budi pekerti, sopan santun, etika. Oleh karena itu Akhlak biasanya dibagi menjadi dua bagian yaitu: Akhlak yang terpuji dan akhlak yang tercela, Akhlak yang terpuji itulah yang akan menjadi pokok dalam pembicaraan dalam rangka menentukan prinsip-prinsip dasar akhlak.

Adapun penulis uraikan tentang prinsip dasar akhlak yang baik yaitu seseoran0g selalu membiasakan dirinya untuk berbuat kepada hal-hal yang baik dan wajar, karena dalam pembinaan dalam akhlak itu harus dilakukan secara continue didalam lingkungan keluarga atau secara terus menerus sejak anak itu lahir sampai mengakihiri khayatnya bahkan sejak dalam kandungan ibunya sampai mati.

Akhlak Tasawuf adalah merupakan salah satu khazanah intelektual Muslim yang kehadirannya hingga saat ini semakin dirasakan, secara historis dengan teologis akhlak tasawuf tampil mengawal dan memandu perjalanan hidup umat agar selamat dunia dan

${ }^{9}$ Abd. Salam, Model Pendidikan Agama Islam Dengan Pendekatan Tasawuf (Penerapan Tasawuf AlGhali di Sekolah, Pesantren, SMP, SMA dan Perguruan Tinggi), Malang: Penerbitan UMM Pres, 2015, 46.

${ }^{10}$ Nasution M. Yunan, Pegangan Hidup. Jilid 1, (Solo Ramadhani, 1988), 19. 
akhirat. Tidaklah berlebihan jika misi utama kerasulan Muhammad SAW. Adalah untuk menyempurnakan akhlak yang mulia, dan sejarah mencatat bahwa faktor pendukung keberhasilan dakwah beliau itu antara lain karena dukungan akhlaknya yang prima.

Akhlak adalah keadaan jiwa yang menumbuhkan perbuatan dengan mudah dilakukan tanpa perlu berfikir lebih lama. Akhlak dan tasawuf saling berkaitan. Akhlak dalam pelaksanaannya mengatur hubungan horizontal antara sesama manusia, sedangkan tasawuf mengatur jalinan komunikasi vertical antara manusia dengan Tuhannya. Akhlak menjadi dasar dari pelaksanaan tasawuf, sehingga dalam prakteknya tasawuf mementingkan akhlak.

Sumber dari semua akhlak yang tercela adalah kesombongan, peremahan dan kehinaan. Sedangkan sumber semua akhlak yang terpuji adalah kekhusyu'an dan citacita yang mulia. Mengembangkan diri, takjub, dengki, kezaliman, keras kepala, pemaksaan, penindasan, menolak nasihat, egoisme, gila hormat, gila pujian, dan sebagainya bersumber dari kesombongan. Sedangkan kebohongan, kehinaan, pengkhianatan, riya, makar, penipuan, ketamakan, ketakutan, kekikiran, kelemahan, kemalasan, penghambaan kepada selain Allah, penggantian sesuatu yang hina dengan sesuatu yang baik dan sebagainya, semuanya merupakan tanda-tanda kehinaan dan kerendahan diri. ${ }^{11}$

Sedangkan akhlak yang mulia, seperti kesabaran, keberanian, keadilan, kemanusiaan, kearifan, kehati-hatian, santun, pemaaf, sabar, nasihat-menasihati, keagungan jiwa, tawadhu', qana'ah, dapat dipercaya, ikhlas, membalas kebaikan dengan kebaikan yang serupa atau yang lebih besar darinya, melupakan kesalahan orang lain, meninggalkan sesuatu yang tidak bermanfaat, membersihkan hati dari akhlak yang tercela dan sebagainya, semuanya bersumber dari kekhusyu'an dan cita-cita yang mulia.

Allah SWT, menjelaskan tentang bumi yang senantiasa khusyu', kemudian air jatuh diatasnya maka tumbulah tanaman-tanaman yang menghiasinya. Begitu juga manusia, jika ia mendapatkan taufiq dari Allah. Sedangkan api, tabiatnya adalah membakar dan merusak, sehingga menjadi barang yang paling rendah dan hina. Begitu juga manusia jika memiliki sifat-sifat seperti api, maka selalu ingin berada di atas dan sombong.

Akan tetapi jika api itu sudah panas maka akan berubah menjadi hina. Akhlak yang tercela seperti api begitu juga manusia, sedangkan akhlak yang mulia seperti bumi dan begitu juga manusia. Barang siapa mempunyai cita-cita yang mulia dan jiwa yang khusyu', niscaya akan memiliki sifat-sifat yang baik. Barang siapa cita-citanya rendah dan hawa nafsunya tinggi, niscaya akan memiliki sifat-sifat yang tercela.

${ }^{11}$ Ibnul Qayyim Al-Jauziyyah, Terapi Mensucikan Jiwa, (Jakarta, Qisthi Press, 2013), 257-258. 
Ketahuilah bahwa telah diriwayatkan dari mereka berkenaan dengan hal itu dimana hakikatnya seperti buah. Tujuan hal itu adalah apa yang dikatakan oleh Rahimahullah, "Akhlak yang bagus adalah wajah yang cemerlang, memberikan kebaikan, dan menahan diri dari menyakiti orang lain." Dia juga mengatakan, "Dia adalah membuat orang lain ridha dalam keadaan suka maupun duka." Namun dikatakn pula bahwa bukan demikian yang mana semua itu adalah bagian dari buah akhlak yang baik. AlQur'an telah menunjukan kepada akhlak ini ketika menyebutkan ciri-ciri orang Mukmin. ${ }^{12}$

Pembinaan akhlak bukanlah sesuatu proses yang dapat terjadi dengan cepat, tetapi harus berjalan sedikit demi sedikit atau secara berangsur-berangsur sesuai dengan pertumbuhan dan perkembangan yang dilalui supaya dapat menjadi kebiasaan baginya. Selanjutnya dalam perkembangan itu harus diberi petunjuk yang baik, nasehat, menyambut manfaat sesuatu dan bahaya-bahaya serta menjelaskan pada anak-anak tentang hal-hal yang tidak bermanfaat, memperbanyak amal yang baik serta diajarkan berpikir lebih dahulu tentang akibat sesuatu bila ingin mengerjakanya.

Pembinaan akhlak adalah proses pembangunan perilaku santri-santriwati secara bertahap yang dilakukan oleh guru ngaji sebagai implementasi dari iman dan ajaran Islam dalam kehidupan induvidu, keluarga, masayarakat dan negara.

Pembinaan akhlak adalah proses perbuatan, tindakan, penanaman nilai-nilai perilaku budi pekerti, perangai, tingkah laku baik terhadap Allah Subhanahu Wa Ta'ala, sesama manusia, diri sendiri dan alam sekitar yang dilakukan secara berdaya guna dan berhasil guna untuk memperoleh kebahagiaan hidup di dunia dan di akhirat.

Dilihat dari segi model tasawuf adalah mentransfer akhlak yang terpuji dan juga dapat meningkatkan pengetahuan santri-santriwati termasuk juga pengetahuan agama. Sedangkan tujuan tasawuf itu sendiri adalah membentuk dan membina akhlak santri-santriwati, karena akhlak merupakan salah satu ajaran pokok dalalm Islam. Disamping aqidah dan syari'ah bagi kehidupan manusia.

Kalimat tersebut mengandung segi-segi persesuain dengan perkataan "Khalkun” yang berarti kejadian, serta erat hubungan "Khaliq" yang berarti Pencipta dan "Makhluk" yang berarti yang diciptakan. ${ }^{14}$

Pembinaan akhlak yang dikembangkan oleh guru ngaji di TPQ Al-Khairat melalui model-model tasawuf itu sendiri menjadikan santri-santriwati manusia paripurna yang berakhlak mulia serta memiliki keyakinan dan kepribadian yang teguh.

\footnotetext{
12 Jamaluddin Al-Qasim, Buku Putih Ihya 'Ulumudin Imam AL-Ghazali, (PT.Darul Falah-Bekasi), $2013,303$.

${ }^{13}$ Azmi, Muhammad. Pembinaan Akhlak Anak Usia Pra Sekolah. Solo: Belukar, 2006, 56.

${ }^{14}$ Asmaran As, Pengantar Studi Akhlak, (Jakarta: PT. Raja Grafindo, 2002), 2.
} 


\section{Sejarah TPQ Al-Khairat}

Tpq Al-Khairat berdiri pada tanggal 12 Agustus 1999, TPQ ini merupakan TPQ tempat pengajian santri-santriwati dalam bacaan Al-Qur'an, dengan adanya pemikiran pembina TPQ Al-Khairat untuk menyelenggarakan sebuah taman Al-Qur'an didasarkan semangat untuk menciptakan generasi Qur'ani yang memang harus digalakan agar membumi supaya santri-santriwati dapat memperkuat nilai-nilai karakter yang sudah ada dan dapat membentengi diri dengan akhlak dari kemajuan teknologi yang mengglobal.

Tenaga pengajar di TPQ Al-Khairat ini berjumlah 3 orang, yakni 2 orang pengajar laki-laki dan satu orang pengajar perempuan. Pengajar tersebut mengajarkan santri-santriwati menjadi manusia paripurna yang dapat membedakan mana tasawuf yang baik dan mana yang tidak, nilai-nilai tasawuf-nyapun mengajarkan bersikap baik, berucap, dan berpakaian yang sesuai tuntunan syariat Islam.

Jumlah santri-santriwati di TPQ Al-Khairat ini berjumlah 67 orang yakni santri berjumlah 38 orang sedangkan santriwati berjumlah 29 orang diantaranya ada yang SD, SMP dan SMA, bahkan sudah ada yang tamat sekolah.

\section{Model Tasawuf Sebagai Basis Pembinaan Akhlak Santri-Santriwati}

\section{Model Tasawuf Ijma' Ulama}

Tasawuf ijma' ulama adalah yang sesuai syariat Islam, dan tuntutan ijma' ini yakni memperbaiki akhlak dengan akhlak serta menjadi sumber hukum ketiga dalam Islam setelah Al-Qur`ân dan Sunnah. Jadi model tasawuf ijma’ ulama ini yang dapat membina akhlak dari akhlak tercela menjadi akhlak terpuji sehingga para santri-santriwati di TPQ AL-KHAIRAT dapat belajar dan mengenali model tasawuf yang merubah akhlak mereka dari yang tidak baik menjadi baik.

Dengan model tasawuf ijma' ulama santri dapat membedakan mana tasawuf yang bersumber Al-Qur'an dan As-sunnah dan mana yang tidak. Tasawuf ini tidak hanya menuntun santri-santriwati untuk membedakan mana tasawuf ijma' ulama dan mana yang dolalah. Akan tetapi menjadikan santri-santriwati yang konsisten menjaga akhlak mereka dari akhlak yang buruk menjadi akhlak yang baik. Kelebihan dari tasawuf ijma' ulama yakni; 1) Tasawuf ijma' ulama Memperbaiki akhlak dengan akhlak, 2) Tasawuf ijma' ulama mengajar kebaikan sesuai tuntunan Al-Qur'an dan As-Sunnah, 3) Tasawuf ijma' ulama dapat menjadikan akhlak santri-santriwati menjadikan akhlak yang uswatun khasanah, 4) Tasawuf 
ijma' ulama mengajarkan santri-santriwati untuk selalu menjaga hati dari iri, dengki, hasut dan lain-lain.

1. Model tasawuf dolalah

Tasawuf dolalah adalah tasawuf yang tidak sesuai dengan syariat Islam, tasawuf semacam ini kepercayaanya menyembah berhala seperti; patung, pohon yang besar,dan matahari. Adapun karakteristik model tasawuf dolalah ialah; 1) Tasawuf dolalah selalu bertentangan dengan Al-Qr'an dan As-Sunnah, 2) Tasawuf dolalah dapat merusak akhlak, 3) Tasawuf dolalah dapat merusak aqidah, 4) Tasawuf dolalah mencerminkan kesyrikan.

\section{Nilai-nilai Tasawuf Yang Dikembangkan Oleh Guru Ngaji di TPQ Al-Khairat:}

Nilai-nilai tasawuf yang dikembangkan oleh guru ngaji pada TPQ Al-Khairat bertujuan untuk memperbaiki Iman, Islam dan Ihsan. Selain itu, nilai tasawuf tersebut mencerminkan pada jiwa santri-santriwati dalam beriman, beramal, dan berilmu serta berakhlak mulia.

Adapun nilai-nilai tasawuf yang dikembangkan oleh guru ngaji pada TPQ Al-Khairat TPQ Al-Khairat yakni; 1) Selalu Membumikan Al-Qur'an tiap arinya, 2) Keseharianya memakai sarung dan topi, 3) Keseharianya memanfatkan membaca buku, 4) Selalu dekat dengan masjid untuk beribadah kepada Allah SWT, 5) Sabar dalam segala aspek kehidupan, 6) Ketika ia sakit selalu mengucapkan kalimat-kalimat toibah, 7) Konsisten melaksanakan ibadah sholat walaupun dalam keadaan sakit, 8) Selalu berhati-hati dalam berucap dan berbuat.

\section{PENUTUP}

Berdasarkan pembahasan di atas dapat disimpulkan bahwasannya Model-model tasawuf yang diajarkan oleh guru ngaji TPQ Al-Khairat semata-mata sebagai basis pembinaan nilai rohani baik akidah maupuan ahklak santri-santriwati sangatlah penting dilakukan pada setiap jenjang lembaga pendidikan, agar seorang santri/anak memiliki kepribadian yang baik dan terhindar dari pelanggaran-pelanggaran moral, maka perlu adanya pembinaan agama sejak dini karena tasawuf itu sendiri bagian dari ajaran Islam.

Disisi lain perlu adanya kerja sama guru ngaji dengan orang tua santri dan masyarakat dalam merumuskan dan mengawal pembinaan perilaku seorang santri/anak. Mengingat, sebaik apapun pendidikan tasawuf di TPQ Al-Khairat tanpa adanya dukungan orang tua dan masyarakat maka sulit bagi santri-santriwati untuk memiliki kepribadian yang baik. Secara 
praksis, pembinaan nilai-nilai rohani/akhlak dalam membentuk kepribadian seorang santri/anak didik sesungguhnya dimulai sejak anak lahir sampai "'ia dewasa. Ketika lahir diperkenalkan dengan kalimat toyyibah, kemudian setelah mereka tumbuh dan berkembang menjadi anak-anak, yang pertama harus ditanamkan nilai-nilai rohani yang berkaitan dengan keimanan, sehingga anak mengenal dan meyakini Allah SWT dengan seyakin-yakinya/ma'rifatullah.

Bersama dengan itu, seorang anak/peserta didik juga dibimbing dengan nilai-nilai rohani, seperti cara tutur kata yang baik, berpakaian yang baik, bergaul dengan baik, dan lain-lain. Selain itu, peserta didik juga ditanamkan sifat-sifat yang baik, seperti nilai-nilai yang dikembangkan guru ngaji TPQ Al-Khairat ini yakni ; Selalu Membumikan Al-Qur'an tiap arinya, Keseharianya memakai sarung dan topi, Keseharianya memanfatkan membaca buku, Selalu dekat dengan masjid untuk beribadah kepada Allah SWT, Sabar dalam segala aspek kehidupan, Ketika ia sakit selalu mengucapkan kalimat-kalimat toibah, Konsisten melaksanakan ibadah sholat walaupun dalam keadaan sakit, Selalu berhati-hati dalam berucap dan berbuat. 


\section{DAFTAR PUSTAKA}

Al-Qasim Jamaluddin, Buku Putih Ihya 'Ulumudin Imam AL-Ghazali, (PT.Darul FalahBekasi), 2013.

Asmaran As, Pengantar Studi Akhlak, (Jakarta: PT. Raja Grafindo, 2002).

Ibrahim dan Nana Sudjana, Penelitian dan Penelitian Kualitatif, (Bandung : Sinar Baru, 1989).

Muhammad Azmi,. Pembinaan Akhlak Anak Usia Pra Sekolah. Solo: Belukar, 2006.

M. Yunan Nasution, Pegangan Hidup. Jilid 1, (Solo Ramadhani, 1988).

Ni'am Syamsun, Tasawuf Studies, Pengantar Belajar Tasawuf, Yogyakarta: Ar-Ruzz Media, 2014).

Salam Abd., Tasawuf Jalan Rohani Menuju Allah, (Malang: Penerbitan UMM Pres, 2015).

Syukur M. Amin, Tasawuf kontekstual, Solusi Problem Manusia Modern, (Yogyakarta, Pustaka Pelajar, 2003).

Suryapratondo Suparlan, Ilmu Jiwa Kepribadian, (Jakarta : PT. Paryu Berkah, 1984).

Salam Abd., Model Pendidikan Agama Islam Dengan Pendekatan Tasawuf (Penerapan Tasawuf Al-Ghali di Sekolah, Pesantren, SMP, SMA dan Perguruan Tinggi), Malang: Penerbitan UMM Pres, 2015.

Sugiyono, Metode Penelitian Pendidikan Pendekatan Kuantitatif, Kualitatif dan R\&D, (Bandung: Alfabeta, 2009).

Qayyim Al-Jauziyyah Ibnul, Terapi Mensucikan Jiwa, (Jakarta, Qisthi Press, 2013). 